\title{
IAOOS OBSERVATIONS OF AEROSOLS AND CLOUDS IN THE HIGH ARCTIC BY AUTONOMOUS DRIFTING LIDAR PLATFORMS
}

\author{
J. Pelon ${ }^{1}$, C. Di Biagio' ${ }^{2}$, V. Mariage1, P. Genau ${ }^{1}$, L. Loyer ${ }^{1}$, J.-C. Raut ${ }^{1}$, G. Ancellet ${ }^{1}$ \\ ${ }^{1}$ LATMOS, Sorbonne Université-CNRS-UVSQ Paris, France, ${ }^{2}$ LISA, Université Paris-Créteil, France
}

\begin{abstract}
New drifting platforms have been deployed within the French project IAOOS (Ice-Atmosphere-Ocean Observing System) in the Arctic since 2014. Radiation and meteorological parameters are measured at the surface and profiles of aerosol and cloud properties are obtained with autonomous backscatter lidar systems. These platforms are indeed equipped for ocean-ice-atmosphere studies over the Arctic to better understand processes and interactions controlling sea-ice changes [1]. As stations in the Arctic are sparse, they can also be used as reference measurements for satellite observations. They are deployed in the Arctic almost every year and allow to perform regular measurements of the vertical structure and optical properties of the atmosphere in complement to satellite observations. Other data on snow, ice and ocean are simultaneously measured. Comparisons were made with CALIPSO/CALIOP observations. Measurements on the atmosphere are presented and results are discussed.
\end{abstract}

\section{IAOOS OBSERVATIONS}

The upper part of the IAOOS platforms is dedicated to atmospheric measurements. It includes an integrated meteorological station, radiometric sensors, a backscatter lidar (possibly including polarization separation) and a camera. Figure 1 presents the mounting of the platforms. Additional temperature measurements are performed in ice, and upper ocean from a multiple temperature sensor chain [2].

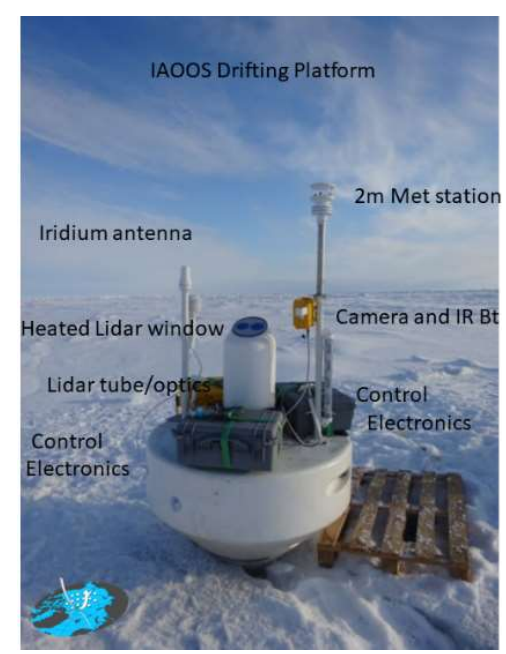

Fig. 1: Implementation of the instrumentation on the IAOOS platform

Other sensors are adapted for temperature, salinity, gases and nutrients for measurements in the ocean [1]. Data are taken at regular intervals (up to 8 times per day) over a given period of time (minutes to an hour) Several platforms can be deployed each year, depending on the opportunities by the collaborations with groups performing ocean campaigns in Arctic, or the possibility to deploy from the Russian Barneo camp in spring at the North Pole. Field measurements are starting in spring or summer and may last up to two years as the platforms are drifting over the Arctic, depending on where they are placed and problems that may occur.

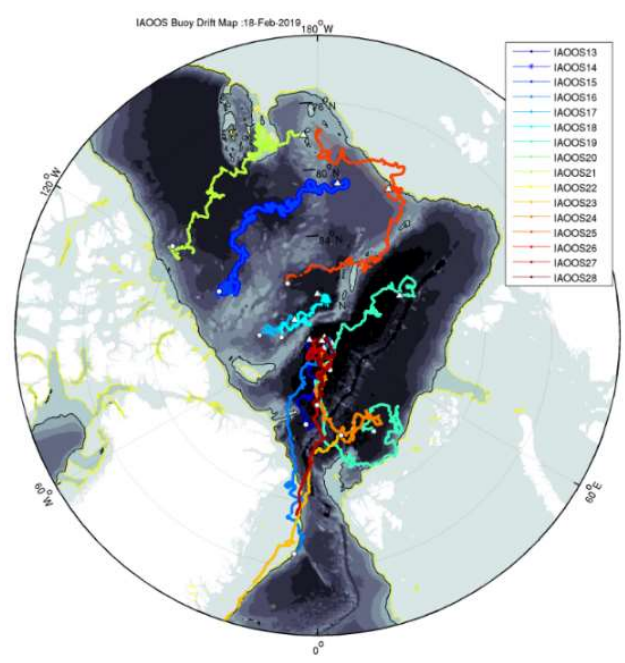

Figure 2 : Trajectories of all deployed IAOOS platforms over high Arctic since 2013, showing the transpolar drift of sea-ice. Depth of Artic ocean correspond to shades of gray. Land is reported as white areas (courtesy N. Sennéchael, LOCEAN/SU).

The sea-ice drift is such as most of the ice exits through the Fram straight between Greenland and Svalbard Islands. Some moves to the Beaufort gyre north of Canada in western Arctic. This can be seen in Fig. 2 presenting the trajectories of all the buoys that have been deployed. Platforms are usually destroyed when they reach the limit of ice 
and ocean, in summer. Some have been crashed in ridges formed by ice floes, some by bears playing with them. Table 2 lists the deployments of platforms equipped with lidars since the beginning of the project, their operation and their duration of operation. Observations are taken over several months and some platforms have provided more than 1,5 year of data, some much less. The deployment is done during ocean cruises, from various ice-breakers in the frame of collaborative international efforts, most particularly with Korea (Araon), Norway (Lance), Germany (Polarstern) and from the North pole station (Barneo).

\begin{tabular}{|c|c|c|c|c|c|}
\hline $\begin{array}{l}\text { Platform } \\
\text { name }\end{array}$ & $\begin{array}{l}\text { Lidar } \\
\text { type }\end{array}$ & Year & Deploy & Location & 0peration \\
\hline IAOOS 4 & back & 2014 & Barneo & N. Pole & $4 / 2014-11 / 2014$ \\
\hline IAOOS 7 & back & 2015 & N-ICE & Svalbard & $1 / 2015-4 / 2015$ \\
\hline IAOOS 9 & Polar & 2015 & N-ICE & Svalbard & $1 / 2015-4 / 2015$ \\
\hline IAOOS10 & back & 2015 & N-ICE & N. Pole & $4 / 2015 / 6-2015$ \\
\hline IAOOS 12 & Polar & 2015 & Pstern & Siberia & - \\
\hline IAOOS 16 & back & 2015 & Araon & Siberia & $9 / 2015-7 / 2016$ \\
\hline IAOOS 20 & back & 2016 & Barneo & N. Pole & 10 days* \\
\hline IAOOS 21 & Polar & 2016 & Barneo & N. Pole & 10 days* \\
\hline IAOOS 23 & back & 2017 & Barneo & N. Pole & $4 / 2017-12 / 2017$ \\
\hline IAOOS 24 & back & 2017 & Araon & Siberia & $4 / 2017-11 / 2017$ \\
\hline IAOOS 25 & back & 2017 & Barneo & N. Pole & $8 / 2017-11 / 2018$ \\
\hline IAOOS 26 & back & 2018 & Barneo & N. Pole & $4 / 2018$ \\
\hline IAOOS 27 & back & 2018 & Barneo & N. Pole & 4/2018- \\
\hline IAOOS 28 & back & 2018 & Oden & N. Pole & $7 / 2018-8 / 2018^{*}$ \\
\hline
\end{tabular}

Table 1. IAOOS Lidar Platforms deployed since 2014

Icing of the window remains an issue, due to the discontinuous operation, although heating is applied at the end of summer.

\section{IAOOS ATMOSPHERIC SYSTEM}

\subsection{Lidar}

The laser systems were designed to be eye-safe (regarding the NF EN 60825-1 norm). Energy was therefore limited, and high operation frequency (up to $10 \mathrm{kHz}$ ) has been selected. The time duration of the sequence was chosen as a compromise between the optimization of the signal to noise ratio, the atmospheric variability, and the sampling need. Vertical sampling resolution is $15 \mathrm{~m}$, but signals are further averaged before transmission (see Table 2). A typical 10 minutes averaging sequence for each profile was adopted. Four sequences a day were aimed at to allow a sampling of cloud properties compatible with inputs/outputs of meteorological model analyses.

The optical head was developed in France at INSU by Division Technique, who also designed the control system and interface. Integration of the lidar system was performed by the French company Cimel, that also designed the photon counting sampling and averaging electronics. Backscattering lidar systems can be implemented with and without polarization discrimination. A similar overall design is used for both systems, including a polarizing device and a polarization splitter at the emission and at the reception of the polarized system. A two-channel reception system is used for dual polarization signal analysis. Detectors are avalanche photodiode from Excelitas used in Geiger mode. Ancillary data are acquired such as those from accelerometers to inform about the tilt angles of the buoy linked to ridge formation and sea-ice breaking. All data are transferred to IPEV (http://iaoos.ipev.fr) using Iridium satellite link. To reduce data transmission costs, vertical averaging is performed in progressively increasing altitude bins (Table 2).

\begin{tabular}{ll}
\hline Parameters & Value \\
\hline & \\
frequency / pulse width & $\sim 5 \mathrm{kHz} / 200 \mathrm{~ns}$ \\
wavelength / bandwidth (FWHM) & $\sim 800 \mathrm{~nm} /<0.6 \mathrm{~nm}$ \\
emitted energy / pulse & $\sim 2 \mu \mathrm{J}$ \\
diameter emission / reception lens & $\sim 70 \mathrm{~mm}$ \\
emission / reception full FOV & $\sim 650 \mu \mathrm{rad}$ \\
detection filter bandwidth (FWHM) & $\sim 0.6 \mathrm{~nm}$ \\
overlap range (90\%) & $\sim 300 \mathrm{~m}$ \\
Sampling vertical resolution & $15 \mathrm{~m}$ \\
Vertical resolution (transmitted data) & $15 \mathrm{~m}[0-1 \mathrm{~km}]$ \\
& $30 \mathrm{~m}[1-3 \mathrm{~km}]$ \\
& $60 \mathrm{~m}[3-15 \mathrm{~km}]$ \\
background noise (average and standard & $120 \mathrm{~m}[15-25 \mathrm{~km}]$ \\
deviation) & 25 to $30 \mathrm{~km}$ \\
\hline
\end{tabular}

Table 2: Typical IAOOS lidar system parameters

Data processing is performed according to [3]. Saturation (or dead time limitation) is corrected for high backscattering signals (as due to clouds and background). Measurements have been made in laboratory using a specific procedure (varying the background level for a given pulse energy received) to check the dead time value. Results were close to that provided by the manufacturer and manufacturer's values are used. In case of dense cloud occurrence at a short distance oversaturation of the APD can be observed, with a strong decrease in signal (undershoot), biasing the cloud return signal. A polynomial fit has been used to correct this undershoot, allowing the recovery of tens of meters of useful signal in the cloud.

The average background signal $\mathrm{B}$ is then calculated in the upper channels (between 25 and $30 \mathrm{~km})$. It is subtracted to the signal $\mathrm{S}(\mathrm{r})$ in each bin. Overlap function $\mathrm{O}(\mathrm{r})$ and calibration constant Cs can then be determined from clear air signal analysis (previously performed during tests 
before expedition and from very clear air profiles observed in Arctic [3]). The attenuated backscatter is derived from the range-corrected signal as

$$
\beta_{a t t}(r)=[S(r)-B] \cdot r^{2} /\left[C_{s} \cdot O(r)\right]
$$

Altitude of cloud and aerosol layers can be determined directly, whereas forward lidar signal inversion is used to determine optical depths and scattering ratio or extinction profiles.

\subsection{Met and radiation}

As seen in Fig. 1 IAOOS platforms are equipped with several meteorological sensors (pressure, temperature, moisture and wind (from sonic anemometer)), and infrared brightness temperature measurement in the $8-12 \mu \mathrm{m}$ region. Lidar is also used as a radiometer to measure the solar radiance scattered at nadir by the sky above. A large bandwidth solar radiometer is also mounted on some platforms. A low cost camera is used to take views of the platform environment during sunlight seasons.

\section{IAOOS ATM. OBSERVATIONS}

An example of time series obtained on the atmosphere, results obtained by the B24 platform set up at the North Pole in 2017 are shown in Figure 3. The variation of the lidar signal background is reported in the upper panel. It is a standard measure of IAOOS, used as a proxy for the downward diffuse solar flux. The sky's brightness temperature $T_{B}$ (which indicates the presence of cloud when $T_{B}$ is high) and the altitude-time cross-section of the attenuated backscattering signal. Areas of strong positive correlations (high particle scattering, high $\mathrm{T}_{\mathrm{B}}$, high diffuse flux) are seen, marking the presence of dense clouds (red rectangles). Areas of small scattering, low TB and small diffuse fluxes marking clear-air atmospheric cases (blue rectangles). Between the two, all types of cloud structures can be observed. This information is used for the determination of radiative flux at the surface and the analysis of the surface energy balance which leads to the melting of snow. The $\mathrm{T}_{\mathrm{B}}$ measurements provide an additional constraint on the optical depth and type of the clouds. Lidar measurements show that the occurrence of supercooled boundary layer clouds can be significantly high. They are predominating in spring, as observed for all deployment years. Aerosols are frequently observed in winter $[2,3]$.

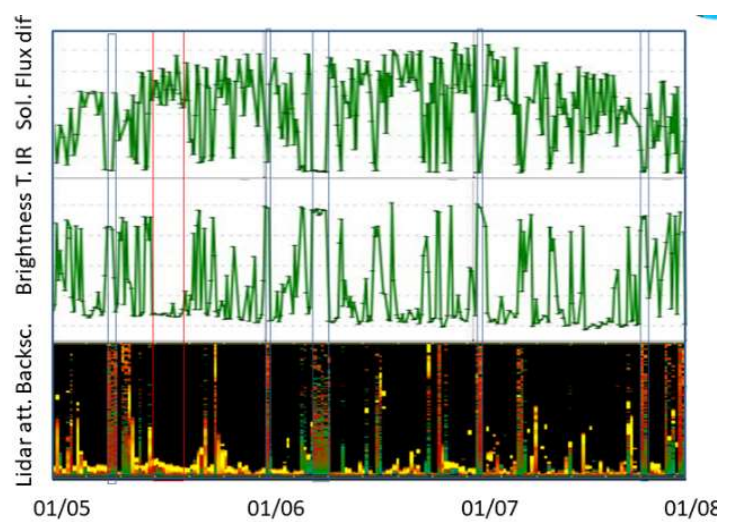

Fig. 3 : Time series of lidar background radiance (top), temperature brightness (middle) and lidar signal between 0 and $5 \mathrm{~km}$ (low) measured by platform B24 from the beginning of May to the end of July 2017, showing cloud and aerosol occurrence observed with the lidar and impact on radiation (see text).

\section{AEROSOL TRANSPORT}

Properties of aerosol have been analyzed over the high Arctic north of Svalbard between October 2014 and June 2015 using the new version 4 (V4)
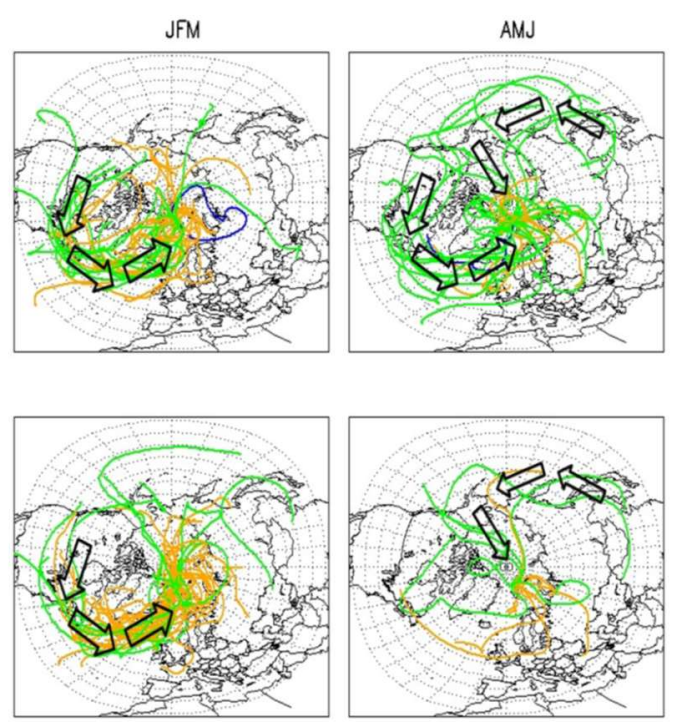

Fig. 4: Backward trajectories for desert dust (upper panel), and polluted dust (lower panel) subtypes in the periods of January to March 2015 (JFM, left) and April to June 2015 (AMJ, right). The color of the trajectories indicates the arrival altitude in the high Arctic: orange 2-5 km, and green 5-10 km). The arrows show principal transport patterns.

CALIPSO (Cloud and Aerosol Lidar and Infrared Pathfinder Satellite Observations) data [see AMT special issue]. Space-borne observations indicate a maximum in aerosol occurrence at the end of winter attributed to low-level $(0-2 \mathrm{~km})$. Midtropospheric $(2-5 \mathrm{~km})$ particles are mostly identified by CALIOP (Cloud and Aerosol Lidar with Orthogonal Polarization) as highly 
depolarizing. Systematic trajectories have been performed for all aerosol layers identified by CALIOP. The analysis of backward trajectories indicates that below $2 \mathrm{~km}$ aerosols originate mostly from Russia and Europe, while above 2 $\mathrm{km}$ significant sources are also North America and the Pacific areas. Fig. 4 reports trajectories for dust and polluted dust.

\section{IAOOS AND CALIPSO OBSERVATIONS}

Results from IAOOS drifting platforms have been compared to CALIOP observations for a few cases of CALIOP identified dust types. Fig. 5 shows an example of the attenuated scattering ratio (attenuated backscatter divided by the molecular backscattering derived from a model) profile obtained by IAOOS on February $14^{\text {th }}$, 2015. The aerosol content measured by IAOOS

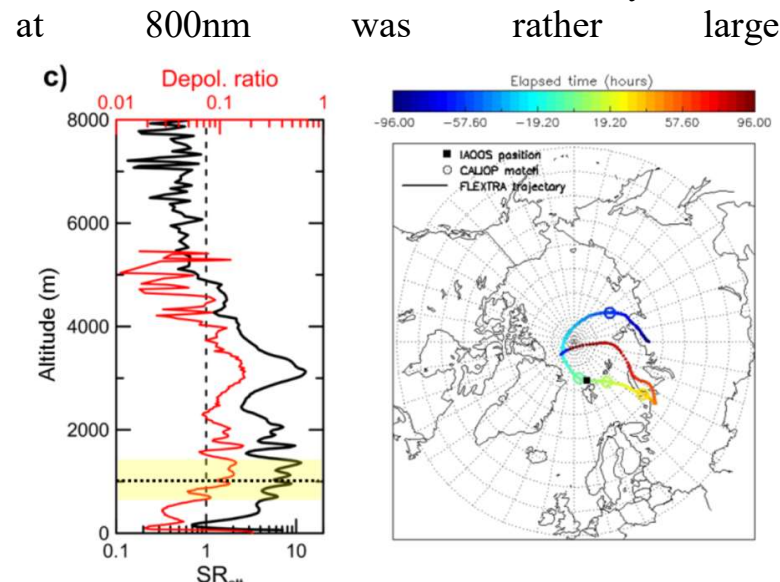

Fig. 5: Left:: Attenuated backscatter ratio (SRatt) and pseudo-depolarization ratio vertical profiles measured by IAOOS lidar at $800 \mathrm{~nm}$ on February $14^{\text {th }}, 2015$. The horizontal dotted line indicates the altitude at which the FLEXTRA backward and forward trajectories were performed, while the yellow band shows the vertical interval $( \pm 0.5 \mathrm{~km})$ used for CALIOP data analysis. Right: Map showing the 4 days backward and forward FLEXTRA trajectories.

(IAB 7.3 $\times 10^{-3} \mathrm{sr}^{-1}$ ), and CALIOP identified the presence of aerosols both along backward and forward trajectories from the IAOOS position. On February 14th, the dominant subtypes identified by CALIPSO were dusty marine at 1 $\mathrm{km}$ and polluted dust at $3 \mathrm{~km}$. Rather highdepolarization ratios (larger than 10\%) in both layers are indicative of the presence of nonspherical particles. Assuming that clear air is observed on this IAOOS profile above $5 \mathrm{~km}$, as suggested by an extended range of altitude where $\mathrm{SR}_{\text {att }}$ is low and almost constant, one can determine that the two-way transmission due to particle scattering and absorption is about $60 \%$ (see Fig. 5). The IAB retrieved for the 14 February IAOOS profile combined with the measured transmission allows to estimate an average IAOOS lidar ratio (LR) of $27( \pm 6) \mathrm{sr}$ at $800 \mathrm{~nm}$, for the aerosol layer between 0 and 5 $\mathrm{km}$, considering measurement uncertainties of $\pm 10 \%$ for both transmission and IAB and multiple scattering correction [2]. It corresponds to a $532 \mathrm{~nm}$ lidar ratio of $29( \pm 8) \mathrm{sr}$ assuming the spectral dependence proposed by [4]. This value better corresponds to ice clouds (LR 25-30 sr at $532 \mathrm{~nm})$ possibly including clean continental particles (LR 35 sr). Pure desert dust, polluted dust or polluted particles/smoke, or Arctic haze having much larger LR values [4].

\section{CONCLUSION}

Observations provided by IAOOS platforms deployed in the Arctic allow to characterize super-cooled boundary layer clouds frequently observed in spring and elevated aerosol layers in winter. Comparisons with space-borne CALIOP observations lead to suggest that the aerosol classification in Arctic may be biased by the occurrence of diamond dust.

Acknowledgements: The IAOOS program has been developed in partnership with LOCEAN at SU and funded by the Agence Nationale de la Recherche (ANR-10-EQPX-32-01). This work was supported by funding from the ICE-ARC program from the EU FP7, grant 603887, ICE-ARC 072. We thank the DT/INSU/CNRS for the preparation of the buoys, deployment, and survey during N-ICE. The N-ICE2015 campaign was supported by the Norwegian Polar Institute' s Centre for Ice, Climate and Ecosystems (ICE)

\section{REFERENCES}

[1] Provost, C., et al. (2015), IAOOS (Ice-AtmosphereArctic Ocean Observing System, 2011-2019), Mercator Ocean Quart. Newsl., 51, 13-15. [http://www.mercatorocean.fr/]

[2] Mariage, V., J. Pelon, F. Blouzon, S. Victori, N. Geyskens, N. Amarouche, C. Drezen, A. Guillot, M. Calzas, M. Garracio, N. Wegmüller, N. Sennéchael, and C. Provost (2017), IAOOS microlidar-on-buoy development and first atmospheric observations obtained during 2014 and 2015 arctic drifts, Optics Express, 25 (4), A73-A84.

[3] Di Biagio, C., Pelon, J., Ancellet, G., Bazureau, A., \& Mariage, V. (2018), Sources, load, vertical distribution, and fate of wintertime aerosols north of Svalbard from combined V4 CALIOP data, ground-based IAOOS lidar observations and trajectory analysis.J. Geophys. Res., 123.

[4] Cattrall, C., Reagan, J., Thome, K., \& Dubovik, O. (2005), Variability of aerosol and spectral lidar and backscatter and extinction ratios of key aerosol types derived from selected Aerosol Robotic Network locations. J. Geophys. Res, 110, D10S11. 